\title{
DÜBLIN
}

Technological University Dublin

ARROW@TU Dublin

2016-10

\section{A Pilot Study of Comparison Gesture Analysis in Motion Driven Video Games}

\author{
Fabrizio Valerio Covone \\ Technological University Dublin, fabrizio.covone@tudublin.ie \\ Brian Vaughan \\ Technological University Dublin, brian.vaughan@tudublin.ie \\ Charlie Cullen \\ Technological University Dublin, charlie.cullen@tudublin.ie
}

Follow this and additional works at: https://arrow.tudublin.ie/aaschmedcon

Part of the Behavior and Behavior Mechanisms Commons, Experimental Analysis of Behavior Commons, Graphics and Human Computer Interfaces Commons, and the Psychology of Movement Commons

\section{Recommended Citation}

Covone, F.V., Vaughan, B. \& Cullen, C. (2016) A Pilot Study of Comparison Gesture Analysis in Motion Driven Video Games, Motion in Games 2016,, 2016, Burlingame, CA, USA, October 10-12. doi;10.1145/ 2994258.2994284

This Conference Paper is brought to you for free and open access by the School of Media at ARROW@TU Dublin. It has been accepted for inclusion in Conference Papers by an authorized administrator of ARROW@TU Dublin. For more information, please contact arrow.admin@tudublin.ie, aisling.coyne@tudublin.ie, gerard.connolly@tudublin.ie.

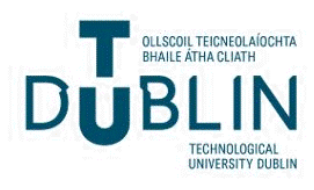




\title{
A Pilot Study of Comparison Gesture Analysis in Motion Driven Video Games
}

\author{
Fabrizio Valerio Covone, Dr. Brian Vaughan, Dr. Charlie Cullen ${ }^{\ddagger}$ \\ Dublin Institute of Technology
}

\begin{abstract}
This study investigates whether there are significant differences in the gestures made by gamers and non-gamers whilst playing commercial games that employ gesture inputs. Specifically, the study focuses on testing a prototype of multimodal capture tool that we used to obtain real-time audio, video and skeletal gesture data. Additionally, we developed an experimental design framework for the acquisition of spatio-temporal gesture data and analysed the vector magnitude of a gesture to compare the relative displacement of each participant whilst playing a game.
\end{abstract}

Keywords: motion analysis, Kinect, motion capture, humancomputer-interaction, video games

Concepts: •Human-centered computing $\rightarrow$ User studies; Gestural input; Empirical studies in HCI;

\section{Introduction}

The increasing research studies in gestures acquisition technologies, how they can be used to improve the way we interact with user interfaces and with the surrounding environment, have led to an increase of research in gesture recognition. We propose that this existing work on gestures can be applied within the domain of games [Soltani et al. 2012] with gesture acquisition technologies such as Microsoft Kinect ${ }^{\circledR}$ that now generates significant amounts of information on game-based interactions. For this reason, we developed a Multimodal Capture Tool (MCT) (Figure 1) that uses a Microsoft Kinect 1 to generate and record two motion capture skeletons at a resolution of 30 Frames Per Second (FPS). The tool also captures audio (WAV) and video (QuickTime ${ }^{\circledR}$ ) which it stores alongside the XML Mo-Cap data for further analysis and annotation.

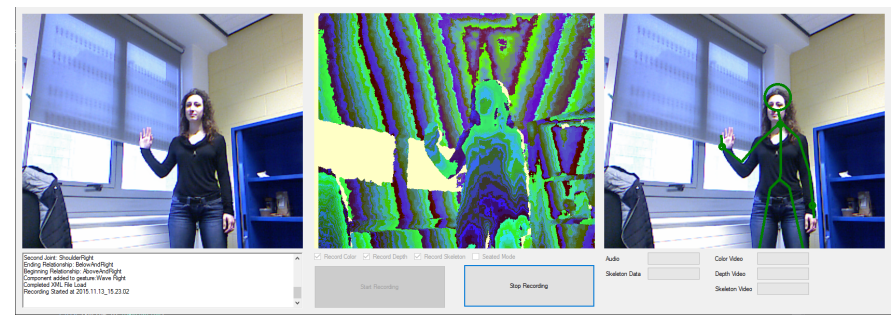

Figure 1: Data Acquisition Process - Screenshot from the prototype Multimodal Capture Tool

\footnotetext{
*e-mail:fabrizio.covone@dit.ie

†e-mail:brian.vaughan@dit.ie

$\ddagger$ e-mail:charlie.cullen@dit.ie
}

Permission to make digital or hard copies of part or all of this work for personal or classroom use is granted without fee provided that copies are not made or distributed for profit or commercial advantage and that copies bear this notice and the full citation on the first page. Copyrights for thirdparty components of this work must be honored. For all other uses, contact the owner/author(s). (c) 2016 Copyright held by the owner/author(s).

MiG '16, October 10-12, 2016, Burlingame, CA, USA

ISBN: 978-1-4503-4592-7/16/10

DOI: http://dx.doi.org/10.1145/2994258.2994284

\section{Experimental Design}

Sixteen participants were selected out of an initial pool of twentyone volunteers based on their answers to an online questionnaire related to their gaming experience. During the survey, the participants were asked to self-assess their gaming proficiency by specifying the amount of time spent playing games. Additionally, they were asked whether they had prior knowledge of Super Smash Bros. (SSB), Mario Kart 8 (MK8) and Mario Tennis (MT). Lastly, if they had prior experience with the games adopted, they were asked which level of familiarity they had with these games. Consequently, the non-gamer group was taken from those who spent less than ten hours per week playing games and also expressed a lack of familiarity with the games involved.

\section{Experimental Setup}

Based on the survey's results, a total of sixteen participants were selected who could be separated equally between the two different groups. A total of eight experimental sessions were carried out, with each session involving one gamer and one non-gamer. The participants were required to play three different Wii-U games; Super Smash Bros. (SSB), Mario Kart 8 (MK8) and Mario Tennis (MT) during three consecutive seven minute gaming sessions (Figure 2).

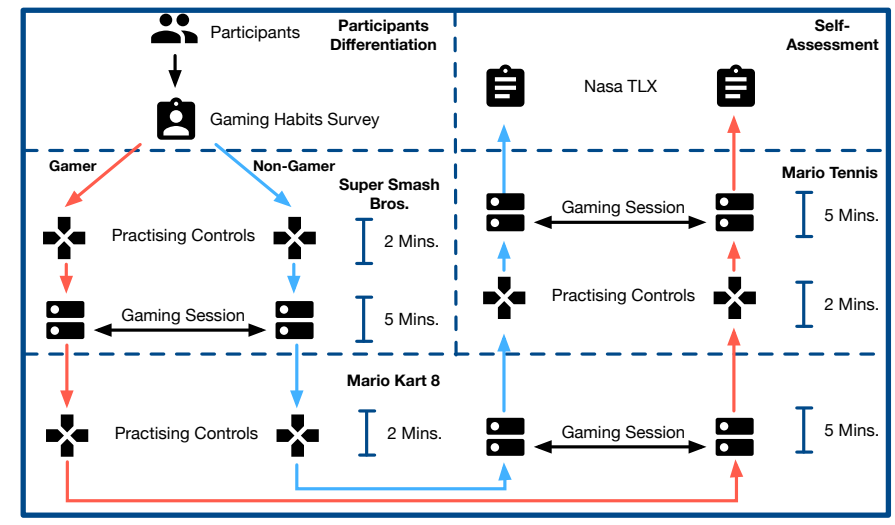

Figure 2: Experimental Design and Workflow - The diagram shows the process carried out during the experiment

\section{Experimental Results}

The Mo-Cap skeleton data for participants was obtained using the Multimodal Capture Tool at 30 FPS. Each frame contained a list of $3 \mathrm{D}$ vectors that give information about position $(J)$ for twenty skeletal joints. It also provided information about the global rotation $(G R)$ and relative rotation $(R R)$ of twenty skeletal limbs as quaternions. These raw data were then reduced to an analysis of vector magnitude over time $(M / t)$ as shown in equation 1 .

$$
M_{j}(t)=\left|\sum_{l=o}^{L} \vec{J}_{l}(t)\right|
$$


Where:

$t \quad:$ Time

$M_{j}$ : Magnitude of Joints' Position

$L \quad$ : Total Number of Joints

$\vec{J}_{l}$ : Single Joint Position

The resulting data sets showed an overall trend of higher mean $(\mu)$ and standard deviation $(\sigma)$ values for gamers compared to nongamers. An important result is the consistent success rate $(p<0.01$ and $r \approx 1.0$ ) of Spearman's correlation test for the standard deviation value $(\sigma)$ of joints' position and limbs' relative rotation throughout SSB's and MK8's sessions. These results have shown to be statistically significant by Mann-Whitney U's significance test $(U \gg 0, \alpha \approx 1.0$ and $Z \approx 0.0$ ).

\section{Gesture Space Results}

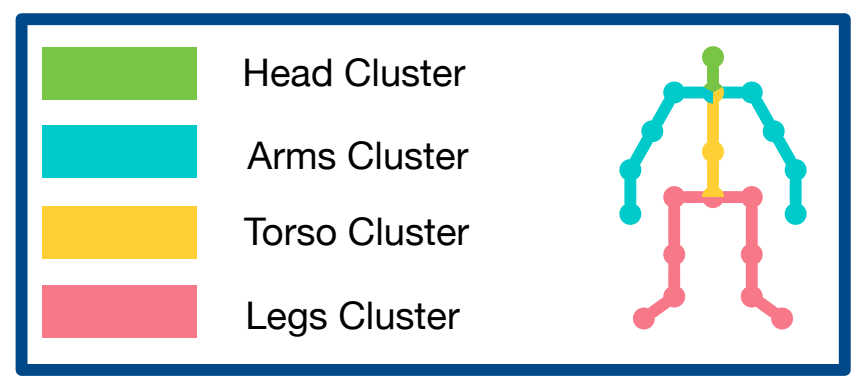

Figure 3: Skeletal Fragmentation Diagram

The Mo-Cap data were segmented (Figure 3) into four clusters of skeletal joints and limbs. This approach was based on McNeill's Gesture Space [McNeill 1992] and Kendon's Gesture Units theory [Kendon 2004]. This process highlighted seventeen correlations ( $p<0.05$ and $r \approx 1.0$ ). Furthermore, their significance was confirmed by using Mann-Whitney U's test $(U \gg 0, \alpha \approx 1.0$ and $Z \approx 0.0$ ).

\begin{tabular}{c|c|c|c}
\cline { 2 - 4 } & SSB & MK & MT \\
\hline Head & $\sigma_{J}, \sigma_{G R} *$ & $\sigma_{J}$ & \\
\hline Torso & $\sigma_{J}, \sigma_{G R}$ & $\sigma_{J}, \sigma_{G R}$ & $\sigma_{G R^{*}}$ \\
\hline Arms & $\sigma_{J}$ & $\sigma_{J}, \sigma_{R R}$ & \\
\hline Legs & $\sigma_{J}, \sigma_{R R}$ & $\sigma_{J}, \sigma_{R R}$ & $\mu_{R R^{*}, \sigma_{R R}}$
\end{tabular}

Table 1: Cluster Results - Summary

\section{Cognitive Load Results}

The Nasa TLX test done by the participants at the end of the session assessed the cognitive load required by the experiment. These tests showed that Gamers considered the task they were presented more mentally demanding than Non-Gamers. While, Non-Gamers rated the experimental sessions very frustrating, exertive and time demanding.

\section{Conclusions}

This experimental study sought to investigate whether there are significant differences in the gestures made by gamers and non-gamers and led to the conclusions that Gamers may stress the movements of certain body parts more while playing video games with limited movement drive. Additionally, Mario Tennis presents an inaccuracy in body movements measurements and this limitation was exploited by Gamers based on their prior knowledge. Lastly, the higher mental demand reported by Gamers may be explained by considering the correlation between the level of expertise of video game players and their visual attention and encoding in short-term memory [Wilms et al. 2013].

\section{References}

Kendon, A. 2004. Gesture - Visible Action as Utterance. Cambridge University Press, Cambridge.

MCNEILl, D. 1992. Guide to Gesture Classification, Transcription and Distribution. In Hand and Mind: What Gestures Reveal about Thought. The University of Chicago Press, Chicago and London, ch. 3, 75-104.

Soltani, F., Eskandari, F., And Golestan, S. 2012. Developing a gesture-based game for deaf/mute people Using microsoft kinect. Proceedings - 2012 6th International Conference on Complex, Intelligent, and Software Intensive Systems, CISIS 2012, 491-495.

Wilms, I. L., Petersen, A., AND VAngKilde, S. 2013. Intensive video gaming improves encoding speed to visual short-term memory in young male adults. Acta Psychologica 142, 1, 108118. 